\title{
Spatial-Temporal variations of vegetation and the relationship with precipitation in summer-A case study in the hilly area of central Sichuan province
}

\author{
Xinrui Luo ${ }^{1}$, Wunian Yang $^{1}$, Liang Liu ${ }^{1}$, Yuhang Zhang ${ }^{1}$ \\ ${ }^{1}$ Key Laboratory of Geoscience Spatial Information Technology of Ministry of Land and Resources, 610059 Chengdu, China
}

\begin{abstract}
The hilly area of central Sichuan is one of the ecologically fragile regions in the upper reaches of the Yangtze River, and it is also the main part of ecological engineering construction. The ecological environment in the study area is related to the ecological security in the middle and lower reaches of the Yangtze River. Recent years have witnessed a great change in vegetation cover in this area as a result of climate change. Therefore, it is necessary to identify the changing patterns of vegetation cover and the impacts of climate change on the vegetation cover change in the study area. In this paper, the characteristics of vegetation cover change over the past 15 years were analyzed, based on the dataset of MODIS NDVI from 2001 to 2015 as well as the climate data from 55 meteorological stations, with methods such as maximum value composite (MVC), linear regression and correlation coefficient. The results showed that the annual maximum average NDVI in the hilly areas of central Sichuan has increased at a rate of 5.84/10a $(P<0.01)$, while the summer average NDVI has increased at a rate of $1.6 / 10 \mathrm{a} \quad(P>0.1)$. The spatial distribution of annual NDVI significantly increased (31.58\%) was greater than the significantly decreasing trend $(2.90 \%)$. Besides, areas with significantly positive correlation and significantly negative correlation between NDVI and precipitation in summer accounted for $16.91 \%$ and $2.5 \%$ of the total area, respectively. And, the correlation between NDVI and precipitation in summer was different in different regions.
\end{abstract}

\section{Introduction}

Climate change and human activities are major driving factors of changes in global terrestrial ecosystems and regional terrestrial ecosystems ${ }^{[1-2]}$. Vegetation, as one of the important components of the ecosystem, interacts with the soil, atmosphere, and water as well as other elements of the entire ecosystem ${ }^{[3]}$.The normalized different vegetation index (NDVI), as an indicator of vegetation cover and vegetation vitality, has become an important parameter for assessing productivity and vegetation growth of the regional and global terrestrial ecosystem all over the world ${ }^{[4-5]}$. Research by $\mathrm{Li}^{[6]}$ and Eastman $^{[7]}$ showed that the response of vegetation to global climate change has obvious spatial and temporal heterogeneity, based on the dataset of NOAA. For example, vegetation increased dramatically during the growing season in the mid-high latitudes of the Northern Hemisphere, while the vegetation changes in the low latitudes are greater. $\mathrm{Qu}^{[8]}$ and $\mathrm{Fu}^{[9]}$ et al used GIMMS/NDVI and MODIS/NDVI respectively to indicate that NDVI can provide a large amount of phenological information of vegetation, and changes in temperature and precipitation have caused vegetation phenological phases to advance or hysteresis, especially in arid and semi-arid regions of China ${ }^{[10-12]}$. There are also studies showing that different ecological types of vegetations have different responses to climate change and human activities ${ }^{[13-15]}$.

In recent years, China has paid more and more attention to ecological environment. Sichuan has become the first pilot point for the construction of the national ecological project. It has successively introduced the "returning farmland to forests and grass projects " and "natural forest resources protection projects" in 1999 and 2000 , respectively. As a region with the lowest vegetation coverage in Sichuan province, the Hilly area of central Sichuan has a large agricultural population, with a high rate of cultivation, and the cultivated land dominated by the sloping land. Besides, it is worth mentioning that, together with unscientific utilizition of land resource deforestation, the problem that the texture of local soil is soft and vulnerable to erosion and weathering, reasonably lead the hilly area of Sichuan to become one of regions with the most serious soil erosion in the upper reaches of the Yangtze River. Consequently, the ecological status of the hilly area in central Sichuan is extremely particular, and its ecological environment is related to the ecological security in the middle and lower reaches of the Yangtze river. Research by Zheng ${ }^{[16]}$ et al monitored the variation of vegetation in Sichuan based on GIMMS/NDVI and MODIS/NDVI, they believed that 
the NDVI has declined from 1982 to 2013. Liu ${ }^{[17]}$ and Wang $^{[18]}$ et al used the GIMMS/NDVI to quantify the dynamic changes of vegetation in the Jialing river basin. They also considered that the tendency of vegetation changes is different in different research phases. Yang ${ }^{[19]}$ et al aimed to analyze the characteristics of landscape pattern changes in the hilly area of central Sichuan, and concluded that high vegetation cover types gradually loses its advantage. Scholars often used the GIMMS/NDVI provided by NOAA (at a spatial resolution of $8 \mathrm{~km}$ ), however, MODIS/NDVI (at a spatial resolution of $250 \mathrm{~m}, 2001-2015)$ utilized in this study. This paper design to analyze the relationship between vegetation variations and meteorological factors in the study area combined with meteorological data. Ultimately, we can establish a scientific evidence for regional vegetation protection and soil erosion management as well as ecological project.

\section{Materials and Methods}

\subsection{Study Area}

The hilly area of central Sichuan is a typical Tabular Mountains and Hilly area in China, with the lowest level of forest coverage in Sichuan (area: $8.4 \times 10^{4} \mathrm{KM}^{2}$ ), located in the central of Sichuan Basin. The study area is characterized by a temperate subtropical monsoon climate, the average annual temperature is approximately 16 to $18{ }^{\circ} \mathrm{C}$, precipitation is about $900-100 \mathrm{~mm} / \mathrm{a}$. The hilly area of central Sichuan, with a cultivation rate of $50-70 \%$, becomes the major producer of grain in Sichuan and local crops mainly include rice, corn, cotton, sugar cane and rapeseed.

\subsection{Data Source}

\subsubsection{Acquisition of MODIS data}

The MODIS13Q1 NDVI(250 m,16-day) dataset used in this study were obtained from the Geographical Information Monitoring Cloud Platform for the period from 2001 to 2015 (http://www.dsac.cn/), and the annual maximum NDVI is calculated by Maximum Value Composite (MVC) ${ }^{[20]}$, efficiently removed the "noise" in all time series from cloud, atmosphere and Solar altitude angle.

\subsubsection{Meteorological data}

The annual average temperature and precipitation data were collected from 2001 to 2015 from China Meteorological Data Service Center (http://data.cma.cn/). This paper adopt the Kriging Interpolation Method based on the NDVI spatial resolution.

\subsection{Methods}

\subsubsection{Linear regression}

Linear regression was used to simulate the inter-annual variation of vegetation for each pixel, thereby reflecting the spatial-temperate variation of vegetation in the study area. The slope of regression was calculated by the least squares method (Equation 1) ${ }^{[21]}$ :

$$
\boldsymbol{\theta}_{\text {slope }}=\frac{n \times \sum_{i=1}^{n}\left(i \times N D V I_{i}\right)-\sum_{i=1}^{n} i \sum_{i=1}^{n} N D V I_{i}}{n \times \sum_{i=1}^{n} i^{2}-\left(\sum_{i=1}^{n} i\right)^{2}}
$$

Where $\theta_{\text {slope }}$ is the slope of regression; $\mathrm{n}$ is the number of years (equal to 15 in this paper), and $N D V I_{i}$ represents the annual maximum NDVI value or summer NDVI value in the $i^{\text {th }}$ year. When the $\theta_{\text {slope }}>0$, NDVI is increasing; when the $\theta_{\text {slope }}<0$, NDVI is decreasing.

\subsubsection{Correlation analyses}

To assess the impact of climatic factors on vegetation in Hilly area of central Sichuan, we calculated the Pearson's correlation coefficients for NDVI, precipitation and temperature pixel by pixel (Equation 2) ${ }^{[22]}$. The statistics significance of correlation was assessed using the student's t-test at the 95\% (Equation 3).

$$
\begin{aligned}
& r_{\mathrm{xy}}=\frac{\sum_{i=1}^{n}\left(x_{i}-\bar{x}\right)\left(y_{i}-\bar{y}\right)}{\left(\sum_{i=1}^{n}\left(x_{i}-\bar{x}\right)^{2} \sum_{i=1}^{n}\left(y_{i}-\bar{y}\right)\right)^{1 / 2}} \\
& t=\frac{r_{x y}}{\left(\frac{1-r_{x y}^{2}}{n-2}\right)^{1 / 2}}, d f=n-1
\end{aligned}
$$

Where $r_{x y}$ is the correlation coefficient between $x$ and $y$, with a value ranging from -1 to $1 ; x_{i}$ and $y_{i}$ are the summer NDVI and summer precipitation in the $i^{t h}$ year, respectively; $\bar{x}$ and $\bar{y}$ are the mean NDVI and mean precipitation in summer from 2001 to 2015 , respectively.

\section{Result and discussion}

\subsection{Spatial-Temporal variations of vegetation NDVI in the hilly area of central Sichuan}

Figure 1a showed the annual maximum NDVI has increased at a rate of 5.84/10 a $(P<0.01)$ from 2001 to 2015 in the hilly area of central Sichuan. The trend was divided into two phases: phase of rapid increase (2001-2010), accounting for $86.67 \%$ of the overall growth; phase of fluctuant increase (2011-2015), with the maximum NDVI in 2013(0.80).

This paper simulated the variation of vegetation for each pixel based on the linear regression. According to the result of $F$-test, the variation of annual maximum NDVI in the study area was divided into four types (Figure 1b). The result demonstrated that the area of vegetation improvement significantly was 2 times of that the area of vegetation degradation significantly, indicating that vegetation restoration in the study area show an expecting perspect from 2001 to 2015. Areas with increasing in vegetation cover in hilly area of 
central Sichuan were mainly distributed in the middle reaches of the Jialing River basin, such as Nanbu country, langzhong country and yilong country and so on. However, these areas where NDVI was significantly decreased were closed to the city center, such as Meishan (Dongpo district), Luzhou city, Guangan city (Wusheng country, Yuechi country) and Nanchong city, etc, which may be related to urban expansion. Taking Nanchong city as an example, the building area in 2005 was 2.4 times that of 2000 , and it increased by $58.67 \mathrm{~km}^{2}$. In the course of urban development, large-scale agriculture land was occupied due to the construction of urban infrastructure and transportation infrastructure, causing adverse effects on vegetation.

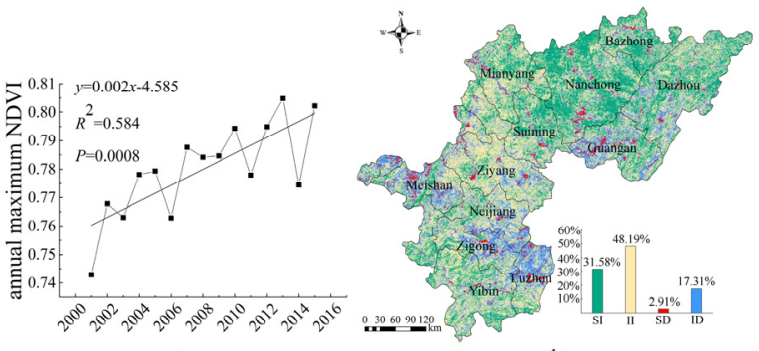

$\mathrm{b}$

Fig.1. The spatial-temporal variation trend of annual maximum NDVI in the hilly area of central Sichuan from 2001 to 2015 (SI: Significant Increasing; II: Insignificant Increasing; SD: Significant Decreasing; ID: Insignificant Decreasing)

\subsection{Relationship of vegetation NDVI changes with precipitation in summer}

Precipitation in Sichuan is mainly concentrated in summer. The curves (Figure 2a, b) showed the variations of average precipitation and average NDVI in summer, respectively, both of them increased from 2001 to 2015 . The maximum average precipitation in summer observed in $2005(661 \mathrm{~mm})$, while the minimum precipitation observed in 2006(253 mm). Moreover, the maximum and minimum annual average NDVI value in summer observed in 2013 (0.75) and 2001(0.66), respectively.

Figure $2 \mathrm{c}$ indicated that areas where summer average NDVI showed a significant positive correlation with summer average precipitation accounted for $16.91 \%$ of the total study area, mainly distributed in Dazhou city (Dazhu country and Qu country), Guangan city (Lingshui country and Guangan country) and Yingshan country, etc. However, areas with significant negative correlation between NDVI and precipitation in summer accounted for $2.5 \%$ of the study area, such as Meishan city, Pujiang country and Qianwei country, etc. Which rainfall is abundant, there is sufficient water for vegetation to grow. Therefore, the increase of precipitation may restrain the photosynthesis of vegetation.
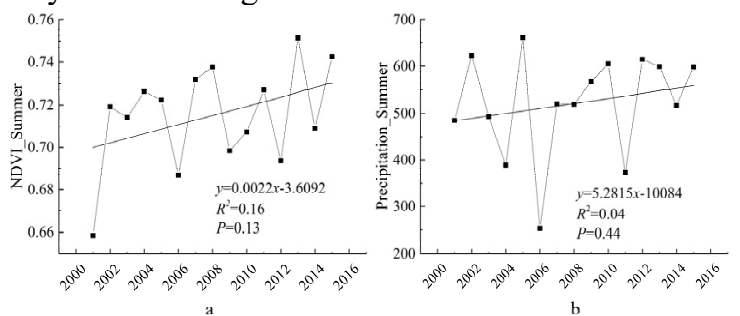

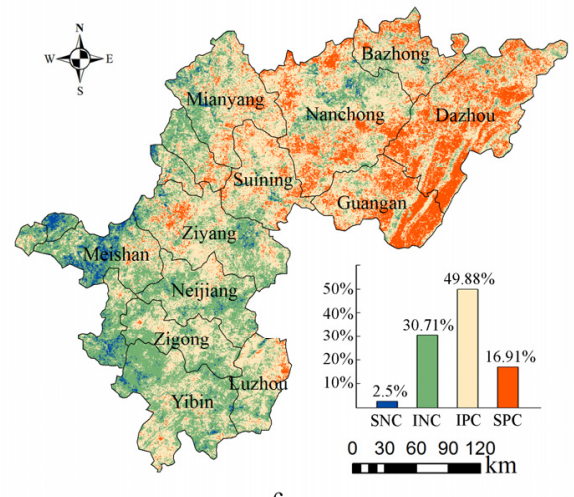

Fig.2. The inter-annual variation trend of average precipitation

(a) and annual average NDVI in summer (b) from 2001 to 2015; and the Spatial distribution of the correlation coefficients between NDVI and precipitation(c) and temperature (d) in study area. (Sinificant Negative Correlation(SNC); Insinificant Negative Correlation(INC); Insignificant Positive Correlation(IPC); Significant Positive Correlation(SPC))

\section{Conclusion}

The main conclusions of the hilly area in central Sichuan province are summarized as follows. First, the maximum annual NDVI has shown an increasing trend, at a rate of 5.84/10a $(P<0.01)$ from 2001 to 2015. Second, the areas where vegetation NDVI increased were mainly distributed in the middle reaches of the Jialing River. While, the areas where the NDVI of vegetation was reduced were closed to the center of the city. Finally, there is a significant correlation between precipitation and NDVI in summer.

\section{References}

1. H. Haberl, K.H. Erb, F. Krausmann, et al. Quantifying and Mapping the Human Appropriation of Net Primary Production in Earth's Terrestrial Ecosystems. Proceedings of the National Academy of Sciences of the United States of America, 104 (2007): 12942-12947

2. B. He, L. Huang, Z.Y. Chen, et al. Weakening Sensitivity of Global Vegetation to Long-Term Droughts. Science China Earth Sciences,6(2018): 1-11

3. H. Sun, C. Wang, Z. Niu. Analysis of the Vegetation Cover Change and the Relationship between Ndvi and Environmental Factors by Using Noaa Time Series Data. Journal of Remote Sensing, 266 (1998): 153-161

4. S. Eckert, F. Hüsler, H. Liniger, et al. Trend Analysis of Modis Ndvi Time Series for Detecting Land Degradation and Regeneration in Mongolia. Journal of Arid Environments, 113 (2015): 16-28

5. C.B. Field. Global Change. Sharing the Garden. Science, 294 (2001): 2490

6. A.N. Li, W. Deng, S.L. Liang, et al. Investigation on the Patterns of Global Vegetation Change Using a Satellite-Sensed Vegetation Index. Remote Sensing, 


\section{2 (2010): 1530-1548}

7. J.R. Eastman, F. Sangermano, E.A. Machado, et al. Global Trends in Seasonality of Normalized Difference Vegetation Index (Ndvi), 1982-2011. Remote Sensing, 5 (2013): 4799-4818

8. B. Qu, W. Zhu, S. Jia, et al. Spatio-Temporal Changes in Vegetation Activity and Its Driving Factors During the Growing Season in China from 1982 to 2011. Remote Sensing, 7 (2015): $13729-13752$

9. Fuyang, Chenhui, Niuhuihui, et al. Spatial and temporal variation of vegetation phenology and its response to climate changes in qaidam basin from 2000 to 2015. Journal of Geographical Sciences, 28 (2018): 400-414

10. S.P. Dai, B. Zhang, H.J. Wang. Spatio-Temporal Change of Vegetation Index Ndvi in Northwest China and Its Influencing Factors: Spatio-Temporal Change of Vegetation Index Ndvi in Northwest China and Its Influencing Factors. Journal of Geo-Information Science, 12 (2010): 315-321

11. Q.H. Li, Y. L.Chen. Response of Spatial and Temporal Distribution of Ndvi to Hydrothermal Condition Variation in Arid Regions of Northwest China During 1981-2006. Journal of Glaciology \& Geocryology, 36 (2014): 327-334

12. M.T. Zhou,J. Li, K.W. Zhu. Changes of NDVI in Different Regions of Northwest Area and Its Responses to Climate Factor. Research of Soil \& Water Conservation, 22(2015): 182-187

13. N.N. Shi, Z.J. Quan, Y. Han, et al. Spatio-Temporal Changes of Vegetation Ndvi and Its Relationship with Regional Climate in Wood-Grass Ecotone of Northeast China During 2000-2010. Research of Soil \& Water Conservation, 23(2016): 175-182

14. M.T. Zhou, L.I. Jun, K.W. Zhu. Spatial-Temporal Dynamics of Different Types of Vegetation Ndvi and Its Response to Climate Change in Xinjiang During 1998-2012. Arid Land Geography, 38(2015): 779-787

15. J.B. Zoungrana, C. Conrad, M. Thiel, et al. Modis Ndvi Trends and Fractional Land Cover Change for Improved Assessments of Vegetation Degradation in Burkina Faso, West Africa. Journal of Arid Environments, 153 (2018): 66-75

16. J. Zheng, W.L. Feng, X.J. Niu, et al. Vegetation Change and Its Correlation with Meteorological Factors in Sichuan Province. Bulletin of Soil \& Water Conservation, 36(2016): 99-104

17. H.H. Liu, P.C. Zhang, X.C. Liu, et al. Temporal and Spatial Variation of Vegetation in Jialing River Basin. Resources \& Environment in the Yangtze Basin, 20 (2011): 111-115

18. G. Wang, X.N. Zhang, Y.Y. Liu, et al. Annual and Seasonal Variation Characteristics of Ndvi and Its Relationship with Meteorological Factors in Jialing River Basin. Journal of Hohai University, 41 (2013): $21-25$
19. L. Yang, M. Zhang, M.L. Luo, et al. Landscape Pattern Change of Vegetation Coverage in Hilly Area of Central Sichuan, Southwest China Based on Modis Ndvi. Chinese Journal of Ecology, 32 (2013): 171-177

20. S.S. Liu, Q. Zhang, X.C. Li, et al.. Temporal and Spatial Variations of Vegetation Cover in Xinjiang from 2002 to 2015 and Their Response to Climate.IOP Conference Series: Earth and Enviromental Science, 74(2017): 12-21

21. Z.G. Tang, J.H. Ma, H.H. Peng, et al. Spatiotemporal Changes of Vegetation and their Responses to Temperature and Precipitation in Upper Shiyang River Basin. Advances in Space Research, 60 (2016)

22. D. Stow, S. Daeschner, A. Hope, et al. Variability of the Seasonally Integrated Normalized Difference Vegetation Index across the North Slope of Alaska in the 1990s. International Journal of Remote Sensing, 24 (2003): 1111-1117

23. Y.Y. Liu, B.J. Liu. Study on Temporal-Spatial Change of Vegetation Cover in Upper Yangtze River from 2001 to 2010. Yangtze River,45(2014): 18-22

24. G.L. Gao, S.Y. Wang, R. Jiang. Remote Sensing Analysis on Vegetation Cover and Landscape Patterns Change in Cuiping. Research of Soil \& Water Conservation, 20 (2013): 104-109 